\title{
Sketching as a Technique to Elicit Information and Cues to Deceit in Interpreter-Based Interviews
}

\author{
Aldert Vrij \\ Sharon Leal \\ Ronald P. Fisher \\ Samantha Mann \\ Gary Dalton \\ Eunkyung Jo \\ Alla Shaboltas \\ Maria Khaleeva \\ Juliana Granskaya \\ Kate Houston \\ Author Note
}

Aldert Vrij, Sharon Leal, Samantha Mann and Gary Dalton, Department of Psychology, University of Portsmouth; Ronald P. Fisher, Department of Psychology, Florida International University; Eunkyung Jo, Department of Psychology, Hallym University; Allla Shaboltas, Maria Ivanova, Juliana Granskaya, Department of Psychology, St. Petersburg State University; Kate Houston, Department of Public Affairs and Social Research, Texas A\&M International University.

This work is funded by the High-Value Detainee Interrogation Group, DJF15-1299-V-0010271 awarded to the University of Portsmouth (UK). Any opinions, findings, conclusions, or recommendations expressed in this article are those of the authors and do not necessarily reflect the views of the U.S. Government. 
Correspondence concerning this article should be addressed to Aldert Vrij, Department of Psychology, University of Portsmouth, King Henry Building, King Henry 1 Street, PO1 2DY, Hants, United Kingdom. Email: aldert.vrij@port.ac.uk 


\begin{abstract}
We tested the effect of sketching while providing a narrative on eliciting information, eliciting cues to deceit and lie detection in interpreter-absent and interpreter-present interviews. A total of 204 participants from the USA (Hispanic participants only), Russia, and the Republic of Korea were interviewed in their native language by native interviewers or by a British interviewer through an interpreter. Truth tellers discussed a trip they had made; liars fabricated a story about such a trip. Half of the participants were instructed to sketch while narrating, the other half received no instruction. Sketching resulted in more details provided. It also elicited cues to deceit: Complications and new details differentiated truth tellers from liars in the Sketching-present condition only. Liars and truth tellers were more correctly classified in the Sketching-present than in the Sketching-absent condition. More complications and more common knowledge details were reported without than with an interpreter.
\end{abstract}




\section{General audience summary}

We tested the effect of sketching while providing a narrative on obtaining information from truth tellers and liars in interpreter-absent and interpreter-present interviews. We hypothesized that sketching while narrating would lead to more new information than just narrating, particularly in truth tellers. Sketching while narrating helps truth tellers to remember better and to report better what they remember. Liars may be unable to include as many details as truth tellers because they lack the imagination to fabricate these details or are unwilling to say much out of fear that this will give leads to investigators that they are lying. In the experiment, 204 participants from the USA (Hispanic participants only), Russia, and the Republic of Korea were interviewed in their native language by native interviewers or by a British interviewer through an interpreter. Truth tellers discussed a trip they had made during the last twelve months; liars fabricated a story about such a trip. Half of the participants were invited to sketch while narrating, whereas the other half of the participants were not requested to sketch. As predicted, sketching resulted in more new information, particularly amongst truth tellers. The presence of an interpreter did not affect these results.

Keywords: interpreter, drawing, non-native speakers, information gathering, deception 


\section{Sketching as a Technique to Eliciting Information and Cues to Deceit in Interpreter-Based Interviews}

Verbal differences between truth tellers and liars are often small (DePaulo et al., 2003; Hartwig \& Bond, 2011). Researchers therefore started to devise theorybased methods to elicit or enhance verbal differences between truth tellers and liars (Vrij \& Granhag, 2012, 2014). The general approach is to exploit differences between truth tellers and liars in how they report activities or events and then to develop methods to magnify those differences (Granhag \& Hartwig, 2015; Vrij, Fisher, \& Blank, 2017)

A typical finding in deception research is that truth tellers provide more detail than liars (Amado, Arce, \& Fariña, 2015; Masip, Sporer, Garrido, \& Herrero, 2005; Oberlader, Naefgen, Koppehele-Gossel, Quinten, Banse, \& Schmidt, 2016). Liars lack the imagination and skills to convey the amount of detail that truth tellers convey (Vrij, 2008), or are reluctant to provide many details out of fear that such details may provide leads for investigators to check (Nahari, Vrij, \& Fisher, 2014a). One theorybased method to capitalize on this difference is to encourage interviewees to provide more information. Truth tellers should take advantage of this and generate more information, whereas liars will be unable or reluctant to provide the same amount of additional information. In the current experiment, we examined the effect of the request to sketch while discussing an event on truth tellers' and liars’ narratives. Drawing a sketch while narrating has been shown to increase the amount of information generated amongst truth tellers (Dando, Wilcock, \& Milne, 2009; Leins, Fisher, Pludwinsky, Robertson, \& Mueller, 2014; Mattison, Dando, \& Omerod, 2015). Sketches have also been used in deception research (e.g. Leins, Fisher, \& Vrij, 2012; Leins, Fisher, Vrij, Leal, \& Mann, 2011; Roos af Hjelmsäter et al., 2014; Vrij et 
al., 2010) but in those deception studies the interviewees did not speak while sketching. They did speak while narrating in the current experiment.

Sketching while narrating may elicit additional information in truth tellers for several reasons. First, sketching serves to reinstate context, which itself enhances recall (encoding specificity principle, Thomson \& Tulving [1970] and Tulving \& Thomson [1973]). Second, sketching, a visual output, is more compatible with visually experienced events. In alignment with the Cognitive Interview principle of “code compatible output” (Fisher \& Geiselman, 1992), this should facilitate recalling visual or spatial information. Third, sketching probably slows down the output process, which would then afford the interviewee more time to think about the event. More time for retrieval is likely to enhance recall. Fourth, sketching implies a subtle request for more precise infromation than a verbal response. That is, when drawing a sketch, one must locate the sketched person/object in a specific location (i.e., put the person/object in a specific location in a room), a fact that might not be included in a verbal response (“Joe was there”—but not indicating where Joe was) (Vrij, Mann, Leal, \& Fisher, 2012).

In the present experiment truth tellers and liars first answered some general questions about an event followed by a final, more specific, question. When answering the final question some participants were asked to draw a sketch and others were not. A request to sketch may enhance differences between truth tellers and liars in terms of details, particularly new details not yet mentioned before. Truth tellers' memory of the event is likely to be richer than the made-up story liars have prepared to tell in advance or can spontaneously fabricate, which should lead to truth tellers reporting more new details when requested to sketch than liars. 
We also examined specific types of detail: Complications and common knowledge details. Complications is one of the criteria included in the verbal veracity tool Criteria-Based Content Analysis (Köhnken \& Steller, 1988; Steller \& Köhnken, 1989). A complication is an activity or event that someone describes which was not expected or planned (Steller \& Köhnken, 1989; Vrij et al., 2017). If someone says that while driving to his holiday destination he had a flat tire en route, that he got lost, and that there was heavy traffic due to a road accident, he reports three complications. Complications are more likely to occur in truthful statements than in deceptive statements (Amado et al., 2015; Vrij et al., 2017). Making up complications requires imagination and many people lack such imagination (Vrij, 2008). In addition, liars prefer to keep their stories simple (Hartwig, Granhag, \& Strömwall, 2007) and including many complications does not constitute a simple story. The increased amount of detail that truth tellers are likely to report when they sketch may well include complications. These are the kind of detail that interviewees are likely to leave out when describing key aspects of activities because complications are often peripheral elements of a story (Vrij et al., 2017).

Common knowledge details refer to strongly invoked stereotypical knowledge about events (e.g. 'We visited the Eiffel Tower. We went up with the elevator and had a lovely view over Paris’) (Vrij et al., 2017). Liars are more likely to include common knowledge details in their statements than truth tellers (Vrij et al., 2017). ${ }^{i}$ Truth tellers, who have personal experiences of an event, are likely to report such unique experiences and when they do so the statement is no longer scripted. If liars do not have personal experiences of the event they report, they then will draw upon general knowledge to construe the event (Sporer, 2016). Even if they have personal 
experiences of the event, they may not report them due to their desire to keep their stories simple (Hartwig, Granhag, \& Strömwall, 2007).

\section{The use of an interpreter}

Investigators increasingly use interpreters in investigative interviews but experimental research examining the effect of the presence of interpreters on eliciting information and cues to deceit is scarce. A consistent finding in the few interpreter experiments is that interpreter-present interviews result in less information than interpreter-absent interviews (Ewens et al., 2016a, b, c, 2017; Vrij et al., 2017). Ewens et al. (2017) suggested two reasons for this. First, interpreters do not translate every detail the interviewee gives. Second, interviewees actually report less with an interpreter present (Ewens et al., 2017). There are two possible reasons for this. The interpreter's interruptions perhaps disrupt the interviewee's train of thought thereby making memory retrieval more difficult (Vrij, Hope, \& Fisher, 2014; Nelson \& Goodmon, 2003). Alternatively, an interviewee may decide to be concise when an interpreter is present given the extra time it takes to communicate through an interpreter, similar to people being more concise when talking to a hard-of-hearing person (Ewens et al., 2017).

We explored the effect of an interpreter on complications and common knowledge details. Vrij et al. (2017) found no effect of an interpreter on these variables but it is important to replicate this to test its robustness. We cannot rule out that the presence of an interpreter has an effect. If interviewees are more inclined to be concise in the presence of an interpreter, this could result in reporting fewer complications and more common knowledge details. Alternatively, interpreters may leave out complications as they are often peripheral elements of a story.

\section{Within-subjects comparisons}


Vrij (2016) recently argued for the development of within-subjects measures in which different responses made by the same interviewee during a single interview are compared. Truth tellers and liars may differ from each other in reporting details on a group basis, but individual differences in providing details makes it difficult to determine whether a single person is telling the truth or lying based on the amount of detail s/he provides (Nahari \& Pazuelo, 2015; Nahari \& Vrij, 2014). Individual differences play a lesser role in within-subjects comparisons in which different responses made by the same interviewee during a single interview are compared. To reduce differences across individuals, we therefore also calculated the proportion of new details (new details / total details) and the proportion of complications (complications / (complications + common knowledge details).

\section{Hypotheses}

We hypothesized the following three main effects:

- Hypothesis 1: Interviewees will provide more total details, more new details and more complications in the Sketching-present condition than in the Sketching-absent condition.

- Hypothesis 2: Truth tellers will provide more total details and more new details, more complications, and fewer common knowledge details than liars and subsequently will obtain a higher proportion of complications than liars.

- Hypothesis 3: Interviewees will provide more total details and more new details in the interpreter-absent interviews than in the interpreter-present interviews. We further hypothesized the following two interaction effects:

- Hypothesis 4: Truth tellers will provide more new details than liars, particularly in the sketch condition. Consequently, the proportion of new details will be higher in truth tellers than in liars, particularly in the sketch condition. 
- Hypothesis 5: Truth tellers will provide more complications than liars, particularly in the sketch condition. Consequently, the proportion of complications will be higher in truth tellers than in liars, particularly in the sketch condition.

\section{Participants}

\section{Method}

A total of 204 University students (52 males, 147 females and five not indicated) took part in the study. Their age ranged from 18-39 years with an average age of $M=22.00$ years $(S D=3.44)$. Participation took place in three different universities in the Republic of Korea, Russia and USA, and the background of the participants was Korean $(n=80)$, Russian $(n=79)$ and Hispanic $(n=45)$, respectively.

\section{Procedure}

Recruitment, pre-condition selection form, preparation and pre-interview questionnaire.

We used the same procedure as Vrij et al. (2017). Participants were recruited via an advert on the university intranets and advertisement leaflets distributed in university buildings. The advert explained that the experiment would require participants to tell the truth or lie about a trip away that they may (or may not) have taken within the last year. We decided upon "last year” so that truth tellers would still remember many details about their trip and liars could not easily say 'I can’t remember' when answering the questions. On arrival to the corresponding university, participants received a participant information sheet and signed an informed consent form. Both truth tellers and liars then completed a selection form that contained six cities that the researchers thought the participants may have visited during the past year. (Different cities were used for the three different countries.) The six cities were 
included on the selection form so that we would obtain some kind of standardization of the cities discussed in the study. The participants were also asked to write down the names of two other cities they had visited during the past year. We did so because if truth tellers had not been to any of the six cities mentioned on the selection form in the past twelve months, they could discuss in the interview one of these two additional cities.

For each city the participants indicated (a) whether they had been there during the last twelve months, (b) when they had been there during the last twelve months, (c) for how long they stayed there, and (d) whether they have lived there. For truth tellers, the experimenter selected one of the six cities where the participant had stayed during the last twelve months for at least two nights but had never lived there. In case a truth teller had stayed in only one of those six cities, that particularly city was chosen. In case a truth teller had stayed in more than one of these six cities the experimenter chose a city, ideally one that had not been discussed by (too) many truth tellers before so that we would obtain a variety of cities being discussed. In case a truth teller had not been to any of the six cities, the experimenter selected one of the additional cities that the truth teller had listed on the selection form. Truth tellers were informed that they would be interviewed about this selected city (city X) and asked to answer the questions truthfully. For liars, the experimenter selected either one of the six cities on the selection form where the liar had never been in his/her life before, or selected a city not on the list but which was discussed by a truth teller during an interview (after checking that the liar had never been to this city before). In other words, the truth tellers' and liars' cities were matched. Liars were informed that they would be interviewed about city $\mathrm{X}$ and that they had to pretend to have stayed there for at least two nights during a trip made during the last twelve months. Across all 
102 truth tellers, more than twenty cities were used. Liars were also interviewed about these cities.

Truth tellers and liars were then left with a computer with internet access and told they had twenty minutes to prepare for their interview, or to inform the experimenter if they were ready before that time. The participants were told that they were allowed to make notes while doing their research. Truth tellers and liars were told that it was important to be convincing because, if they did not appear convincing, they would be asked to write a statement about what they told the interviewer in the interview. In a pre-interview questionnaire the truth tellers and liars rated their thoroughness of preparation via three items: (1) shallow to (7) thorough; (1) insufficient to (7) sufficient; and (1) poor to (7) good. The answers to the three questions were averaged (Cronbach’s alpha $=.81$ ) and the variable is called 'thoroughness'. They were also asked whether they thought they were given enough time to prepare themselves with the following question: 'Do you think the amount of time you were given to prepare was: (1) insufficient to (7) sufficient.

\section{Experimental conditions.}

Participants were allocated randomly to one of the eight experimental cells. A total of 102 participants were allocated to the truth condition and 102 to the lie condition; 100 to the Sketching-absent condition and 104 to the Sketching-present condition; and 101 to the Interpreter-absent condition and 103 to the Interpreter-present condition. Individual cell sizes varied from 24 (two cells) to 27 (two cells). A power analysis revealed that a total of 25 participants would be required in each group for the study to have sufficient statistical power (.993) and a large effect size ( $\eta \mathrm{p} 2=.138)$.

In total, three interpreters were used in the study, one in each country. These were the same interpreters as used in Vrij et al. (2017). The Korean and Hispanic 
interpreters were professional interpreters; the Russian interpreter spoke fluent English and had a Masters degree that included English language. The interpreters were instructed to use a long consecutive interpreter style (Viezzi, 2012): They interpreted chunks of information uttered by the participant rather than interpreting sentence by sentence, and took notes during the interview. All interpreters had experience in using this type of interpreter style.

In the interpreter condition, one British interviewer was used, whereas in the non-interpreter condition one Russian, one Korean and one Hispanic interviewer were used. The British, Russian and Korean interviewers were the same as in Vrij et al. (2017). Prior to the experiment the British interviewer (who is a very experienced interviewer and has interviewed in many experiments before) instructed the other interviewers how to conduct the interview. They were instructed to be friendly and not to interrupt the interviewee. Several practice sessions took place until the British interviewer was satisfied with the interview style of the interviewer. That is, she was satisfied with the demeanour of the interviewers (appeared friendly) and the opportunities they gave to the interviewees to talk (no interruptions). To assess consistency in interview style between the interpreter and non-interpreter conditions, participants were asked to assess in a post-questionnaire the rapport they experienced with the interviewer (see below). All interpreters and interviewers were blind to the veracity condition and hypotheses.

We did not predict any effects for nationality of the participants. In addition, not only nationality but also interviewer and interpreter varied along with nationality. We wanted to control for the possible effects of this, and therefore included site as a covariate in the hypotheses testing analyses.

\section{The interview.}


Prior to the interview the experimenter told the interviewer about which city to interview the participant. The interviewer was unaware of the veracity status of the participant. To make the interviewee feel comfortable and to avoid floor effects in establishing rapport interviewees were offered a glass of water from the interviewer, as offering something helps rapport building (reciprocation principle, Cialdini, 2007).

The interviewer started by asking five general questions about the planning and execution of the trip (e.g. "Please tell me in as much detail as possible everything you did when you were at from the moment you arrived to the moment you left” and "Tell me in as much detail as possible everything you did to plan this trip, e.g. organising transport, accommodation, where to visit and so on”). Since the sketching manipulation was not yet introduced when answering these five questions, the results of these five questions will not be discussed. ${ }^{i i}$ In the sixth and final question the sketching manipulation was introduced. The question was introduced by the following request: "I want you now to think about the best thing that happened when you were there. Take a few moments to picture in your mind where you were and what you saw at that time, including who you were with, descriptions of objects and locations, and the sequence of actions and please let me know when you have done this". After this request the actual question was asked: “Now please tell me everything you remember but while doing this make a sketch of what you could see” (Sketching-present condition); “Now please tell me everything you remember” (Sketching-absent condition). We label this question the 'best moment' question. The participants were given one sheet of A3-sized paper and a set of coloured pencils to make the sketch. They were also reassured that the quality of their drawing did not matter. While the interviewee sketched and talked the interpreter took notes of what 
the interviewee said and conveyed this information to the interviewer at regular times, during which the interviewee stayed quiet.

The interviews were video (interviewees only) and audio recorded and the English speech in the audiotapes was subsequently transcribed. In other words, in the Interpreter-present condition the speech from the interpreter was transcribed. We did this because it is this speech that interviewers will understand in real life interviews with interpreters. In a study where in the Interpreter-present condition the interviewee’s and interpreter's speech were both analysed, virtual identical findings emerged in the interviewee's and interpreter's speech in terms of eliciting information and cues to deceit (Ewens et al., 2017).

\section{Post-interview questionnaire.}

After the interview, participants completed a post-interview questionnaire, which was translated and completed in the participant's native language. The questionnaire measured motivation to perform well during the interview (measured on a 5 -point Likert scale from $1=$ not at all motivated to $5=$ very motivated). In addition, the participants were also asked to indicate the extent to which they told the truth when answering the best moment question on an 11 point Likert scales ranging from $0 \%$ to $100 \%$.

Rapport was measured via the nine items Interaction Questionnaire (Vallano \& Schreiber Compo, 2011). Participants rated the interviewer on 7-point scales ranging from [1] not at all to [7] extremely on nine characteristics such as smooth, bored, engrossed, and involved (Cronbach’s alpha $=.81$ ).

For those participants who were asked to sketch we asked about their experiences. Participants were asked the following four questions that they answered on 7-point scales ranging from [1] not at all to [7] very much so: (a) 'Sketching while 
narrating was easy to do’, (b) 'Sketching while narrating was difficult to do’, (c) 'Sketching while narrating made it easier for me to think what I wanted to say', (d) 'Sketching while narrating made it more difficult for me to think what I wanted to say’. Questions two and four were recoded and the four questions were averaged to form the cluster labelled "easy to sketch and talk” (Cronbach’s alpha $=.79$ ).

\section{Coding}

All coders were blind to the hypotheses and Veracity condition.

\section{Detail.}

The coders were taught the coding scheme by the first author who has more than twenty years of experience in coding detail. A coder first read the transcripts and coded each detail in the interview. A detail is in this study defined as a unit of information about the trip the interviewee allegedly had made. To give an example, the following answer has seven details: "I'm also drawing a plaza that is in front of the cathedral. There was a large fountain. It had a lot of seats, or benches”. Each detail in the answer was coded only once; thus repetitions were not coded. A second coder coded a random sample of 40 transcripts. Inter-rater reliability between the two coders, using the two-way random effects model measuring consistency, was high (Single Measures ICC $=$.89). The first coder than coded to what extent each detail reported in the 'best moment' question was new, that is, not mentioned in the earlier part of the interview (Single Measures ICC $=.95$ ).

Two coders coded independently from each other complications and common knowledge details in all transcripts. A complication is an activity or event that someone describes which was not expected or planned (Steller \& Köhnken, 1989; Vrij et al., 2017). Example of complications are (a) “And my mum was calling me but I still wasn't coming, I was still in the water"; (b) "So I put this cream on my body but 
er I didn't do it quite well, so I still burned my shoulders”; and (c) “It was a large crowd. We came quite late, so we were looking for quite some time to find a place where to stand”. Common knowledge details refer to strongly invoked stereotypical knowledge about events (Vrij et al., 2017). Examples of common knowledge details are: (d) "the best er moment was er my, like spending time at this central square, and um, in my thoughts I was also there, and all my closest people, my relatives were with me and my girlfriend also", (e) "You see all this beauty around you and um, all this cliff um walls, covered with um portraits of saints and er, you feel this special smell in church" and (f) "we like um, just went to the cafe after this and er we were drinking coffee and we weren't talking at all, and we just w-were feeling very very good”.

Inter-rater reliability between the two coders, using the two-way random effects model measuring consistency, was good for complications (Average Measures, Intraclass correlation coefficient, ICC $=.87$ ) and satisfactory (but not strong) for common knowledge details (Average Measures ICC $=.64$ ). Disagreements were resolved between the two coders. Disagreements typically occurred because one coder missed a cue.

\section{Results}

\section{Preparation thoroughness and preparation time}

Two oneway ANOVAs with Veracity as factor and preparation thoroughness and preparation time as dependent variable revealed that truth tellers $(M=4.92, S D=$ $1.07,95 \% C I[4.71,5.1])$ rated their preparation as more thorough than liars $(M=$ 4.17, $S D=0.99,95 \%$ CI $[3.97,4.37]), F(1,202)=26.82, p<.001, d=0.73$. Truth tellers $(M=5.93, S D=1.49,95 \% C I[5.61,6.26])$ also believed more than liars $(M=$ $4.93, S D=1.79,95 \% C I[4.61,5.25])$ that they were given sufficient time to prepare themselves for the interview, $F(1,202)=18.83, p<.001, d=0.75$. These findings are 
not surprising: Truth tellers were requested to recall a true event whereas liars had to fabricate a story. We introduced preparation thoroughness and preparation time as covariates in the hypotheses testing analyses.

\section{Easy to sketch and talk}

A 2 (Veracity) X 2 (Interpreter) ANOVA with easy to sketch and talk as dependent variable revealed a main effect for Veracity, $F(1,100)=6.50, p=.012, d=$ 0.50. Truth tellers found it easier to sketch and talk $(M=4.01, S D=1.36,95 \% C I$ [3.59, 4.42] $)$ than liars $(M=3.26, S D=1.64,95 \% C I[2.83,3.67])$. The Interpreter main effect, $F(1,100)=0.01, p=.930, d=0.01$, and Veracity X Interpreter interaction effect, $F(1,100)=1.52, p=.221$, partial eta ${ }^{2}=0.015$, were not significant. The mean scores indicate that participants did not find this task easy. Actually, $40.0 \%$ of truth tellers and $61.1 \%$ of liars reported that they found it difficult (mean lower than four).

\section{Manipulation Checks}

\section{Rapport.}

An ANOVA with Interpreter as factor and rapport with the interviewer as dependent variable did not show a difference in rapport between the two conditions, $F(1,202)=2.77, p=.097, d=0.23$. The grand mean revealed that the interviewees perceived the rapport with the interviewer as very good $(M=5.60, S D=.82$ on a 7 point scale).

Motivation, time since the trip was made, and percentage truth telling while sketching.

The grand mean showed that the participants were motivated to perform well during the interview ( $M=4.01, S D=.72$ on a 5-point scale). A 2 (Veracity) X 2 
(Sketch) X 2 (Interpreter) ANOVA revealed no significant main or interaction effects, all F's $<3.41$, all p's $>.066$.

Truth tellers were asked on the pre-condition selection form when they made the trip they discussed. On average this trip was made $M=5.48$ months prior to the interview ( $S D=2.96)$. This variable was not correlated with any of the main dependent variables in the study (total detail, new detail, proportion new detail, complications, common knowledge details, or ratio of complications), all $r$ 's $<.11$, all p's > .26).

Truth tellers told the truth significantly more $(M=95.88, S D=12.45,95 \% C I$ $[91.56,100.25])$ than liars $(M=22.08, S D=29.93,95 \% C I[17.43,26.12]), F(1,196)$ $=566.83, p<.001, d=3.48$ ), which means that the manipulation was successful. In addition, participants were somewhat more truthful without sketching $(M=61.36, S D$ $=42.27,95 \% C I[57.59,66.36])$ than when sketching $(M=56.69, S D=44.71,95 \% C I$ $[51.40,60.00]), F(1,196)=4.06, p=.045, d=.11)$. The Veracity X Interpreter interaction effect was also significant, $F(1,196)=10.69, p=.001$, partial eta ${ }^{2}=.05$ ). The presence of an interpreter had no effect on truth tellers, $F(1,100)=3.37, p=$ $.069, d=.41)$, but did affect liars, $F(1,100)=7.53, p=.007, d=.56)$. Liars interviewed with an interpreter reported to have been more truthful $(M=29.66, S D=$ 33.85, 95\% CI $[5.66,22.10])$ than liars interviewed without an interpreter $(M=13.88$, $S D=22.62,95 \%$ CI [21.75,37.56]). All other effects were not significant, all $F$ 's < 3.45 , all $p$ ’s $>.064$

\section{Hypothesis Testing}

A 2 (Sketch) X 2 (Veracity) X 2 (Interpreter) MANCOVA was conducted with the six variables listed in Table 1 as dependent variables and preparation thoroughness, preparation time, and site as covariates. At a multivariate level main 
effects emerged for Sketching, $F(6,188)=4.61, p<.001$, partial eta ${ }^{2}=.13$, Veracity, $F(6,188)=5.54, p<.001$, partial eta ${ }^{2}=.15$, and Interpreter, $F(6,188)=3.53, p=$ .002 , partial $e a^{2}=.10$. At a multivariate level, the Sketch X Veracity interaction effect, $F(6,188)=3.50, p=.003$, partial eta ${ }^{2}=.10$ and Veracity X Interpreter interaction effect, $F(6,188)=3.31, p=.004$, partial eta ${ }^{2}=.09$, were significant, whereas the Sketch X Interpreter interaction effect, $F(6,188)=1.69, p=.126$, partial $e t a^{2}=.05$, and the Sketch X Veracity X Interpreter interaction effect, $F(6,188)=$ 0.82, $p=.559$, partial eta ${ }^{2}=.02$, were not significant. The multivariate effect for the covariate site was significant $F(6,188)=4.22, p=.001$, partial eta ${ }^{2}=.12$, whereas those for preparation thoroughness $F(6,188)=0.92, p=.479$, partial eta ${ }^{2}=.03$ and preparation time $F(6,188)=1.51, p=.178$, partial eta ${ }^{2}=.05$ were not.

\section{Main effects.}

Regarding the Sketch main effect, significant univariate effects emerged for total details, $F(1,193)=22.39, p<.001, d=.68$, new details, $F(1,193)=18.29, p<$ $.001, d=.60$, complications, $F(1,193)=13.65, p<.001, d=.51$, and proportion of complications, $F(1,193)=4.16, p=.043, d=.29$. More total details were reported in the Sketching-present condition $(M=27.47, S D=16.20$, 95\% CI [25.03,29.91] $)$ than in the Sketching-absent condition $(M=19.26, S D=8.11,95 \% C I[16.61,21.59])$; also more new details were reported in the Sketching-present condition $(M=20.58, S D=$ 15.05, 95\% CI $[18.17,22.88])$ than in the Sketching-absent condition $(M=13.32, S D$ $=9.24,95 \%$ CI $[10.82,15.62])$, and more complications were reported in the Sketching-present condition $(M=1.79, S D=1.77,95 \% C I[1.50,2.06])$ than in the Sketching-absent condition $(M=1.04, S D=1.16,95 \% C I[0.75,1.32])$. These results support Hypothesis 1. Finally, the proportion of complications was higher in the 
Sketching-present condition $(M=0.66, S D=0.38,95 \% C I[0.59,0.73])$ than in the Sketching-absent condition $(M=0.55, S D=0.39,95 \% C I[0.48,0.63])$.

Table 1 about here

All the statistical information regarding the Veracity main effect is presented in Table 1. In terms of detail, truth tellers reported more new details and obtained a higher proportion of new details than liars. In terms of the remaining variables, truth tellers reported more complications and fewer common knowledge details than liars, and the proportion of complications was also higher for truth tellers than for liars. With the exception of the variable total details, these findings support Hypothesis 2.

Regarding the Interpreter effect, significant univariate effects emerged for complications, $F(1,193)=7.66, p=.006, d=0.38$ and common knowledge details, $F(1,193)=7.00, p=.010, d=.30$. More complications were reported without $(M=$ $1.71, S D=1.80,95 \% C I[1.41,1.97])$ than with an interpreter $(M=1.14, S D=1.19$, 95\% CI $[0.85,1.41])$ and more common knowledge details were reported without ( $M$ $=0.69, S D=0.67,95 \% C I[0.59,0.81])$ than with an interpreter $(M=0.50, S D=0.58$, $95 \% C I[0.39,0.61])$. Since the effect for total details, $F(1,193)=0.39, p=.534, d=$ .09 , and new details, $F(1,193)=0.58, p=.448, d=.09$, were not significant, Hypothesis 3 was rejected.

\section{Interaction effects.}

At a univariate level, the Sketch X Veracity effect for new details was significant, $F(1,193)=4.65, p=.032$, partial eta ${ }^{2}=.024$. In the Sketching-absent condition, truth tellers $(M=13.47, S D=7.62,95 \% C I[10.69,16.28])$ and liars $(M=$ $13.18, S D=10.64,95 \% C I[10.43,15.99])$ gave a similar amount of new details, $F(1$, 95) $=0.03, p=.876, d=.03$. However, in the Sketching-present condition, truth tellers $(M=24.34, S D=15.61,95 \% C I[20.41,28.47])$ provided more new details 
than liars $(M=16.67, S D=13.51,95 \% C I[12.45,20.67]), F(1,99)=6.86, p=.010, d$ $=.53$. The effect for proportion new details was not significant, $F(1,193)=0.86, p=$ .356 , partial eta $a^{2}=.004$. This partly supports Hypothesis 4 .

The Sketch X Veracity effect for complications was not significant, $F(1,193)$ $=3.76, p=.054$, partial eta ${ }^{2}=.019$, but this interaction effect refers to any type of interaction. As we predicted a directional effect with specific group differences based on theory and research in Hypothesis 5, a more informative test of Hypothesis 5 is to statistically test for significant differences between truth tellers and liars in each of the two Sketch conditions and to compare the groups' effect sizes to understand the magnitude of differences between truth telling pairs and lying pairs in these two Sketch conditions (e.g. Nahari \& Ben-Shakhar, 2011; Shaw et al., 2015; Vrij et al., 2017). See for the relevance of interpreting $d$-values, du Prel, Hommel, Röhrig, and Blettner (2009) and Fritz, Morris, and Richler (2012). In the Sketching-absent condition, truth tellers $(M=1.10, S D=1.16,95 \% C I[10.69,16.28])$ and liars $(M=$ 0.98, $S D=1.17,95 \%$ CI $[10.43,15.99])$ gave a similar amount of complications, $F(1$, $95)=0.62, p=.435, d=.10$. However, in the Sketching-present condition, truth tellers $(M=2.25, S D=1.84,95 \% C I[20.41,28.47])$ provided more complications than liars $(M=1.31, S D=1.57,95 \% C I[12.45,20.67]), F(1,99)=8.58, p=.004, d=$ .55. In other words, the effect size was much larger in the Sketching-present condition $(d=.55)$ than in the Sketching-absent condition $(d=.10)$ and the effect was significant only in the Sketching-present condition. These findings support Hypothesis 5. The effect for proportion complications was not significant, $F(1,193)=$ $0.04, p=.843$, partial eta ${ }^{2}=.000$.

At a univariate level, the Interpreter $\mathrm{X}$ Veracity interaction effect for common knowledge details was significant, $F(1,193)=12.60, p<.001$, partial eta ${ }^{2}=.06$. In 
the Interpreter-absent condition, truth tellers $(M=0.38, S D=0.57,95 \% C I$

$[0,16.0 .51])$ gave fewer common knowledge details than liars $(M=1.02, S D=0.63$, $95 \%$ CI $[0.89,1.25]), F(1,96)=29.29, p<.001, d=1.07$. In the Interpreter-present condition, however, truth tellers $(M=0.44, S D=0.58,95 \% C I[0.29,0.58])$ and liars $(M=0.55, S D=0.57,95 \% C I[0.41,0.69])$ provided a similar amount of common knowledge details, $F(1,98)=1.15, p=.287, d=.19$.

At a multivariate level, no other effects were significant, $F$ 's $<1.51$, $p$ 's $>.17$. Discriminant Analyses.

Table 2 about here

We conducted a series of discriminant analyses to distinguish between truthful and deceptive interviewees in the Sketching-absent and Sketching-present conditions separately. In all cases, the objective group belonging (truthful versus deceptive) was the classifying variable and we present the cross-validation 'leave-one-out' results. Cross-validation assesses the accuracy of a statistical model across different samples, an important step in generalisation (Field, 2009). We ran eight analyses and each analysis included one of the eight variables listed in Table 2 as predictor. We focused on new detail and complications (including the proportion scores in which they are included), because these two variables yielded differential Veracity effects in the two Sketch conditions (e.g. Sketch X Veracity interaction effect). All statistical information is reported in Table 2.

Table 2 shows that complications was a better predictor of Veracity than new details. In the Sketching-present condition complications and the proportion of complications yielded similar effects but in the Sketching-absent condition, the proportion of complications variable was a better predictor of Veracity than the complications variable. Finally, the Sketching-present condition resulted in more 
accurate classifications of truth tellers and liars than the Sketching-absent condition, supporting Hypotheses 4 and 5.

\section{Discussion}

We found three positive effects of sketching while providing a narrative about an event. First, it elicited more information. Obtaining as much detail as possible is a core aspect of an investigative interview (Fisher, 2010), and the request to sketch thus helps investigators to achieve this aim. Second, it elicited cues to deceit as new details and complications differentiated truth tellers from liars in the Sketching-present condition only. Third, it facilitated lie detection as the correct classifications of truth tellers and liars were somewhat higher in the Sketching-present condition than in the Sketching-absent condition.

We replicated Vrij et al.’s (2017) findings that (a) truth tellers report more complications than liars, (b) liars report more common knowledge details than truth tellers and (c) the proportion of complications is higher amongst truth tellers than liars. The combination of truthfulness (complications) and lying (knowledge details) is particularly useful as it allows us to calculate a within-subjects measure (the proportion of complications equals the proportion of cues to truthfulness). This within-subjects measure resulted in superior classification rates, albeit in the Sketching-absent condition only. Practitioners prefer within-subjects measures (Vrij, 2016). Of course, within-subjects measures would be most effective if truth tellers and liars display truly different response patterns. That is, if truth tellers always include more complications than common knowledge details in their statements and liars always include more common knowledge details than complications in their statements. This is not the case and all that can be concluded is that truth tellers included a higher proportion of complications in their statements than liars. Yet, the 
benefit of using within-subject measures compared to between-subjects measures still exists. If just complications is considered, the problem arises that it will not only be affected by Veracity but also by individual differences, such as being naturally detailed and elaborative. Individual differences play a lesser role in within-subjects comparisons, because it is no longer relevant how many complications someone provides (which could be influenced by being naturally detailed and elaborative). Instead, it becomes relevant how many complications in relation to common knowledge details are included (more likely to be influenced by Veracity).

The findings for the presence of an Interpreter were, in part, puzzling. Compared to Interpreter-absent interviews, Interpreter-present interviews resulted in fewer complications (which could be predicted, see Introduction) but also in fewer common knowledge details. A possible explanation for the common knowledge details finding is that interviewees have more opportunity to think during an Interpreter-present than during an Interpreter-absent interview because they can think when the interpreter translates their responses. Perhaps during this enhanced thinking time they fabricated details that made their replies less scripted, resulting in fewer common knowledge details. In addition, in contrast to the Interpreter experiments carried out so far, it did not negatively affect the amount of information provided. We cannot explain this either, also because in the first part of the interview, which is not discussed in this paper, the presence of an interpreter did not affect the amount of information provided either.

Although the use of common knowledge details did differentiate truth tellers from liars in Interpreter-absent interviews, this was not the case anymore in Interpreter-present interviews. In other words, the presence of an interpreter made one cue to deceit disappear. Although truth tellers reported a similar amount of common 
knowledge details in Interpreter-absent $(M=0.38)$ and Interpreter-present $(M=0.44)$ interviews, liars reported more common knowledge details in Interpreter-absent $(M=$ 1.02) than in Interpreter-present $(M=0.55)$ interviews. Interviewees have more opportunity to think during an Interpreter-present than during an Interpreter-absent interview because they can think when the interpreter translates their responses. Perhaps liars used the opportunity to formulate less scripted responses. Apart from this effect, the findings for the use of an interpreter were positive: It did not affect the information provided and it had no effect on the instruction to sketch which means that sketches can be used in both Interpreter-absent and Interpreter-present interviews.

\section{Methodological Consideration}

Three methodological issue merits attention. First, the experiment truth tellers were given the opportunity to prepare themselves. By doing this we avoided a confound between veracity and preparation, as we also gave liars the opportunity to prepare themselves. We believe that the advantage of avoiding a confound outweighs this disadvantage. Also, good interviewing involves giving interviewees ample opportunity to think about the event they are interviewed about (Fisher, 2010).

Second, people can tell many types of lie, not just the outright lie the liars told in the present experiment. We believe that the findings of this paper can be generalized to most outright lies, but caution is needed when other types of lie are taken into account. We do not consider this to be problematic because we are not aware of any reliable lie detection tool that can be used at all times. The method introduced in this paper is probably unsuitable for detecting embedded lies or omissions, but for such lies other tools are available. In embedded lies most of the information someone reports is true except a small but crucial detail (someone admits being present at the crime scene but denies involvement in the crime, or someone 
describes a true experience but lies about exactly when the event took place). In omissions the entire story is true but someone deliberately leaves out a crucial event or activity (someone truthfully describes a meeting but leaves out the presence of one crucial activity: Committing the crime). Some embedded lies are easier to detect than others. The ‘being present but denying involvement' lie is challenging, but someone who lies about the timing when the experience took place is unlikely to be able to provide checkable details that conclusively demonstrate that s/he experienced the event at the time s/he claimed (Nahari, Vrij, \& Fisher, 2014a, b). For detecting omissions, it is probably necessary for investigators to have some evidence related to the crime. They can then compare the interviewee's story with the available evidence and exploit discrepancies by employing the Strategic Use of Evidence technique (Granhag \& Hartwig, 2015).

Third, the ICC for common knowledge details was satisfactory but not strong $($ ICC $=.64)$. Vrij et al. $(2017)$ reported common knowledge details for the first time and achieved exactly the same inter-rater reliability finding for this variable: .64. This suggests that coding common knowledge details is somewhat subjective and not straightforward. Vrij et al. (2017) reported that disagreements between coders occurred because one coder missed a cue. Our coders had the same experience. 


\section{References}

Amado, B. G., Arce, R., Fariña, F. (2015). Undeutsch hypothesis and Criteria Based Content Analysis: A meta-analytic review. The European Journal of Psychology Applied to Legal Context, 7, 3-12.

Doi:10.1016/j.ejpal.2014.11.002

Cialdini, R. B. (2007) Influence: The psychology of persuasion. New York: William Morrow and Company.

Dando, C., Wilcock, R., \& Milne, R. (2009). The Cognitive Interview: The efficacy of a modified mental reinstatement of context procedure for frontline police investigators. Applied Cognitive Psychology, 23, 138-147. doi:

10.1002/acp.1451

Department of the Army. (2006). Human Intelligence Collector Operations (Field Manual 2-22.3). Washington, DC: Headquarters, Department of the Army (United States of America).

DePaulo, B. M., Lindsay, J. L., Malone, B. E., Muhlenbruck, L., Charlton, K., \& Cooper, H. (2003). Cues to deception. Psychological Bulletin, 129, 74-118. Doi: 10.1037/0033-2909.129.1.74

Du Prel, J-B., Hommel, G., Röhrig, B., \& Blettner, M. (2009). Confidence interval or p-value? Deutzches Arzteblatt International, 106, 335-339.

Doi:10.3238/arztebl.2009.0335.

Ewens, S., Vrij, A., Leal, S., Mann, S., Jo, E., \& Fisher, R. P. (2016a). The effect of interpreters on eliciting information, cues to deceit and rapport. Legal and Criminological Psychology, 21, 286-304 DOI: 10.1111/lcrp.12067

Ewens, S., Vrij, A., Leal, S., Mann, S., Jo, E., \& Houston, K. (2017). The effect of the presence and seating position of an interpreter on eliciting information and 
cues to deceit. Psychology, Crime, \& Law, 23, 180-200.

doi:10.1080/1068316X.2016.1239100

Ewens, S., Vrij, A., Leal, S., Mann, S., Jo, E., Shaboltas, A., Ivanova, M., Granskaya, J., \& Houston, K. (2016b). Using the model statement to elicit information and cues to deceit from native speakers, non-native speakers and those talking through an interpreter. Applied Cognitive Psychology, 30, 854-862. DOI: 10.1002/acp.3270

Ewens, S., Vrij, A., Mann, S., \& Leal, S. (2016c). Using the reverse order technique with non-native speakers or through an interpreter. Applied Cognitive Psychology, 30, 242-249. DOI: 10.1002/acp.3196

Field, A. (2009). Discovering statistics using SPSS (third edition). Los Angeles, CA: Sage.

Fisher, R. P. (2010). Interviewing cooperative witnesses. Legal and Criminological Psychology, 15, 25-38. DOI: 10.1348/135532509X441891

Fisher, R. P., \& Geiselman, R. E. (1992). Memory enhancing techniques for investigative interviewing: The cognitive interview. Springfield, Il: Charles C. Thomas.

Fritz, C.O., Morris, P.E., \& Richler, J.J. (2012). Effect size estimates: Current use, calculations and interpretation. Journal of Experimental Psychology: General, 141, 2-18. Doi: 10.1037/a0024338.

Granhag, P. A., \& Hartwig, M. (2015). The Strategic Use of Evidence (SUE) technique: A conceptual overview. In P. A. Granhag, A. Vrij, \& B. Verschuere (Eds.), Deception detection: Current challenges and new approaches (pp. 231-251). Chichester, England: Wiley. 
Hartwig, M., \& Bond, C. F. (2011). Why do lie-catchers fail? A lens model metaanalysis of human lie judgments. Psychological Bulletin, 137, 643-659. doi: $10.1037 / \mathrm{a} 0023589$

Hartwig, M., Granhag, P. A., \& Strömwall, L. (2007). Guilty and innocent suspects’ strategies during interrogations. Psychology, Crime, \& Law, 13, 213-227, doi: $10.1080 / 10683160600750264$.

Köhnken, G. (2004). Statement Validity Analysis and the ‘detection of the truth’. In P. A. Granhag \& L. A. Strömwall (Eds.), Deception detection in forensic contexts (pp. 41-63). Cambridge, England: Cambridge University Press.

Köhnken, G., \& Steller, M. (1988). The evaluation of the credibility of child witness statements in German procedural system. In G. Davies \& J. Drinkwater (Eds.), The child witness: Do the courts abuse children? (Issues in Criminological and Legal Psychology, no. 13) (pp. 37-45). Leicester, United Kingdom: British Psychological Society.

Leins, D., Fisher, R. P., Pludwinsky, L., Robertson, B., \& Mueller, D.H. (2014). Interview protocols to facilitate human intelligence sources’ recollections of meetings. Applied Cognitive Psychology, 28, 926-935. DOI: 10.1002/acp.304

Leins, D., Fisher, R., \& Vrij, A. (2012). Drawing on liars’ lack of cognitive flexibility: Detecting deception through varying report modes. Applied Cognitive Psychology, 26, 601-607. DOI 10.1002/acp.2837

Leins, D., Fisher, R. P., Vrij, A., Leal, S., \& Mann, S. (2011). Using sketch-drawing to induce inconsistency in liars. Legal and Criminological Psychology, 16, 253-265. DOI 10.1348/135532510X501775

Masip, J., Sporer, S., Garrido, E., \& Herrero, C. (2005). The detection of deception with the 
reality monitoring approach: A review of the empirical evidence. Psychology, Crime, \& Law, 11, 99-122. Doi: 10.1080/10683160410001726356

Mattison, M. C. L., Dando, C. J., \& Ormerod, T. C. (2015). Sketching to remember: Episodic free recall task support for child witnesses and victims with autism spectrum disorder. Journal of Autism and Developmental Disorders, 45, 1751-1765. Doi: DOI 10.1007/s10803-014-2335-z

Nahari, G., \& Ben-Shakhar, G. (2011). Psychophysiological and behavioural measures for detecting concealed information: The role of memory for crime details. Psychophysiology, 48, 733-744. DOI: 10.1111/j.14698986.2010.01148.x

Nahari, G., \& Pazuelo, M. (2015). Telling a convincing story: Richness in detail as a function of gender and priming. Journal of Applied Research in Memory and Cognition, 4 , 363-367.

Nahari, G., \& Vrij, A. (2014). Are you as good as me at telling a story? Individual differences in interpersonal reality-monitoring. Psychology, Crime and Law, 20, 573 - 583. Doi:10.1080/1068316X.2013.793771

Nahari, G., Vrij, A., \& Fisher, R. P. (2014a). Exploiting liars' verbal strategies by examining the verifiability of details. Legal and Criminological Psychology, 19, 227-239. Doi: 10.1111/j.2044-8333.2012.02069.x

Nahari, G., Vrij, A., \& Fisher, R. P. (2014b). The Verifiability Approach: Countermeasures facilitate its ability to discriminate between truths and lies. Applied Cognitive Psychology, 28, 122-128. DOI: 10.1002/acp.2974.

Nelson, D. L., \& Goodmon, L. B. (2003). Disrupting attention: The need for retrieval cues in 
working memory theories. Memory and Cognition, 31, 65-76. Doi:

10.3758/BF03196083

Oberlader, V. A., Naefgen, C., Koppehele-Gossel, J., Quinten, L., Banse, R., \& Schmidt, A. F. (2016). Validity of content-based techniques to distinguish true and fabricated statements: A meta-analysis. Law and Human Behavior, 1-63. Doi: 10.1037/lhb0000193

Roos af Hjelmsäter, E., Öhman, L., Granhag, P. A., \& Vrij, A. (2014). Mapping deception in adolescents: Eliciting cues to deceit through an unanticipated spatial drawing task. Legal and Criminological Psychology, 19, 179-188. Doi: 10.1111/j.2044-8333.2012.02068.x

Schank, R., \& Abelson, R. (1977). Scripts, plans, goals and understanding: An inquiry into human knowledge structures. Hillsdale, NJ: Erlbaum.

Shaw, D.J., Vrij, A., Leal, S., Mann, S., Hillman, J., Granhag, P.A., \& Fisher, R.P. (2015). Mimicry and investigative interviewing: using deliberate mimicry to elicit information and cues to deceit. Journal of Investigative Psychology and Offender Profiling, 12, 217-230. Doi: 10.1002/jip.1438

Sporer, S. L. (2016). Deception and cognitive load: Expanding our horizon with a working memory model. Frontiers in Psychology: Hypothesis and Theory, 7, article 420. Doi 10.3389/fpsyg.2016.00420.

Steller, M., \& Köhnken, G. (1989). Criteria-Based Content Analysis. In D. C. Raskin (Ed.), Psychological methods in criminal investigation and evidence (pp. 217245). New York: Springer-Verlag.

Thomson, D. M., \& Tulving, E. (1970). Associative encoding and retrieval: Weak and strong cues. Journal of Experimental Psychology, 86, 255-262. Doi:

10.1037/h0029997 
Tulving, E., \& Thomson, D. M. (1973). Encoding specificity and retrieval processes in episodic memory. Psychological Review, 80, 352-373. Doi: 10.1037/h0020071.

Vallano, J., P. \& Schreiber Compo, N. (2011). A comfortable witness is a good witness: Rapport-building and susceptibility to mis-information in an investigative mockcrime interview. Applied Cognitive Psychology, 25, 960-970. DOI: 10.1002/acp.1789

Viezzi, M. (2012). Simultaneous and consecutive interpreting (non-conference settings). In C. Millan \& F. Bartrina, (Ed.) The Routledge handbook of translation studies, (pp. 377-388). Abingdon: Routledge.

Volbert, R., \& Steller, M. (2014). Is this testimony truthful, fabricated, or based on false memory? Credibility assessment 25 years after Steller and Köhnken (1989). European Psychologist, 19, 207-220. doi:10.1027/10169040/a000200.

Vrij, A. (2008). Detecting lies and deceit: Pitfalls and opportunities, second edition. Chichester: John Wiley and Sons.

Vrij, A. (2016). Baselining as a lie detection method. Applied Cognitive Psychology, 30, 1112-1119. Doi: 10.1002/acp.3288

Vrij, A., Fisher, R., Blank, H. (2017). A cognitive approach to lie detection: A metaanalysis. Legal and Criminological Psychology, 22, 1-21. DOI:10.1111/lcrp.12088

Vrij, A., \& Granhag, P. A. (2012). Eliciting cues to deception and truth: What matters are the questions asked. Journal of Applied Research in Memory and Cognition, 1, 110-117. doi.org/10.1016/j.jarmac.2012.02. 
Vrij, A., \& Granhag, P. A. (2014). Eliciting information and detecting lies in intelligence interviewing: An overview of recent research. Applied Cognitive Psychology, 28, 936-944. DOI: 10.1002/acp.3071.

Vrij, A., Hope, L., \& Fisher, R. P. (2014). Eliciting reliable information in investigative interviews. Policy Insights from Behavioral and Brain Sciences, 1, 129-136. DOI: $10.1177 / 2372732214548592$

Vrij, A., Leal, S., Granhag, P. A., Mann, S., Fisher, R. P., Hillman, J., \& Sperry, K. (2009). Outsmarting the liars: The benefit of asking unanticipated questions. Law and Human Behavior, 33, 159-166. Doi: 10.1007/s10979-008-9143-y.

Vrij, A., Leal, S., Mann, S., Dalton, G. Jo, E., Shaboltas, A., Khaleeva, M., Granskaya, J., \& Houston, K. (2017). Using the Model Statement to elicit information and cues to deceit in interpreter-based interviews. Acta Psychologica, 177, 44-53. Doi: 10.1016/j.actpsy.2017.04.011

Vrij, A., Leal, S., Mann, S., Warmelink, L., Granhag, P. A., \& Fisher, R. P. (2010). Drawings as an innovative and successful lie detection tool. Applied Cognitive Psychology, 4, 587-594. DOI: 10.1002/acp/1627

Vrij, A., Mann, S., Leal, S., \& Fisher, R. (2012). Is anyone there? Drawings as a tool to detect deception in occupations interviews. Psychology, Crime, \& Law, 18, 377-388. DOI: 10.1080/1068316X.2010.498422 
Table 1.

Total Detail, New Detail, Proportion New Detail, Complications, Common Knowledge Details, and Proportion of Complications as a Function of Veracity.

\begin{tabular}{|c|c|c|c|c|c|}
\hline & $\begin{array}{l}\text { Truth } \\
M(S D) 95 \% \text { CI }\end{array}$ & $\begin{array}{l}\text { Lie } \\
M(S D) 95 \% \text { CI }\end{array}$ & $F$ & $p$ (two-tailed) & $\begin{array}{l}\text { Cohen’s d } \\
{[95 \% \mathrm{CI}]}\end{array}$ \\
\hline \multicolumn{6}{|l|}{ Sketch } \\
\hline Total detail & $24.22(13.75)[21.87,27.01]$ & $22.67(13.27)[19.56,24.70]$ & 01.45 & .229 & 0.11 \\
\hline New detail & 19.12 (13.52) [19,56,24.70] & $14.92(12.22)[12.22,17.18]$ & 05.51 & .020 & 0.33 \\
\hline Proportion new details & $0.76(0.24)[0.70,0.81]$ & $0.62(0.34)[0.56,0.67]$ & 10.98 & .001 & 0.48 \\
\hline Complications & $1.70(1.65)[1.43,2.02]$ & 1.15 (1.39) [0.80, 1.39] & 08.34 & .004 & 0.36 \\
\hline Common knowledge details & $0.41(0.57)[0.28,0.51]$ & $0.77(0.64)[0.69,0.92]$ & 22.95 & $<.001$ & 0.60 \\
\hline Proportion of complications & $0.71(0.28)[0.66,0.81]$ & $0.50(0.37)[0.40,0.55]$ & 21.53 & $<.001$ & 0.65 \\
\hline
\end{tabular}


Table 2

Hit Rates for total detail and proportions of complications as a function of Veracity.

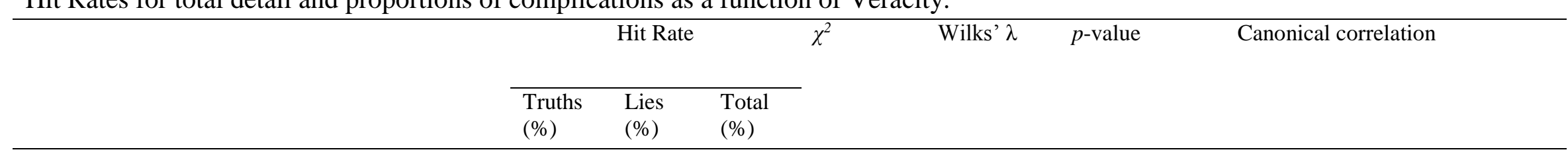

\section{Sketch}

New detail (no sketch)

New detail (sketch)

Proportion of new detail (no sketch)

Proportion of new detail (sketch)

Complications (no sketch)

Complications (sketch)

Proportion of complications (no sketch)

Proportion of complications (sketch)

$\begin{array}{lllll}----- & ----- & ---- & 00.03 & 1.00 \\ 49.1 & 74.5 & 61.5 & 06.89 & 0.93 \\ ---- & ---- & ---- & 02.70 & 0.97 \\ 69.8 & 54.9 & 62.5 & 11.80 & 0.89 \\ ---- & ----- & ---- & 00.27 & 1.00 \\ 64.2 & 72.5 & 68.3 & 07.39 & 0.93 \\ 57.1 & 68.6 & 63.0 & 06.05 & 0.94 \\ 73.6 & 64.7 & 69.2 & 09.91 & 0.91\end{array}$

$\begin{array}{ll}.875 & .16 \\ .009 & .26 \\ .100 & .17 \\ .001 & .33 \\ .603 & .05 \\ .007 & .27 \\ .014 & .25 \\ .002 & .31\end{array}$


${ }^{\text {i }}$ Common knowledge details differ somewhat from the better known term 'scripts'. In Schank and Abelson's definition (1977, p.41) a script refers to a sequence of events (e.g., 'John went to a restaurant. He ordered lobster. He paid the check and left'). The scripted events deception researchers refer to (Vrij et al., 2017, but see also Köhnken, 2004; Sporer, 2016; Volbert \& Steller, 2014) do not necessarily involve a sequence of events (e.g. 'We went to the National Museum where we spent a few hours'). To avoid confusion with scripts, Vrij et al. (2017) called them common knowledge details.

ii There was no difference in the number of details truth tellers and liars reported in these five questions, $F(1,202)=0.42, p=.516, d=.09$. 